\title{
OS RECURSOS DIDÁTICOS MULTIMODAIS E AS TECNOLOGIAS NO ENSINO DE GEOGRAFIA E HISTÓRIA NA PÓS-MODERNIDADE ${ }^{1}$
}

\author{
Augusto Russini ${ }^{2}$ \\ Elsbeth Léia Spode Becker ${ }^{3}$
}

\begin{abstract}
Resumo: Neste artigo, apresentamos a condição pós-moderna do estudante contemporâneo, influenciado pelas tecnologias e com acesso à pluralidade de recursos de textos e imagens, e a escola, ainda formatada em modelos tradicionais de ensino. O recorte de investigação, neste artigo, está ancorado nos componentes curriculares de Geografia e História, no Ensino Fundamental. Frente ao descompasso entre escola e estudante trazemos indicações de possibilidades de utilização de recursos didáticos multimodais como uma opção de ensino-aprendizagem mais atrativa e significativa no cenário pós-moderno. No que concerne aos procedimentos metodológicos foi realizada uma pesquisa bibliográfica sobre a pós-modernidade e os sujeitos pós-modernos, as práticas docentes de Geografia e História e as multimodalidades e os recursos didáticos. As análises das referências apontam para a importância da utilização das tecnologias e dos recursos didáticos multimodais no ensino destas disciplinas como fundamentais no itinerário formativo dos estudantes na atualidade.
\end{abstract}

Palavras-chave: estudantes; ensino-aprendizagem; texto; imagem.

1 O presente artigo é decorrente da dissertação de mestrado intitulada "O ensino de Geografia e História na pós-modernidade: os desafios e as possibilidades das multimodalidades e das tecnologias" realizada no Mestrado Acadêmico em Ensino de Humanidades e Linguagens da Universidade Franciscana (UFN).

2 Graduação em História Licenciatura pela Universidade Franciscana (UFN), Graduação Tecnológica em Processos Gerenciais Centro Universitário de Maringá (UNICESUMAR), Mestrado em Ensino de Humanidades e Linguagens pela UFN e Doutorando em Educação pela Universidade Luterana do Brasil (ULBRA). Docente do Colégio Fundação Bradesco - Gravataí, RS. E-mail: augustorussini.sm@gmail.com.

3 Graduação em Geografia (Bacharelado e Licenciatura) pela Universidade Federal de Santa Maria (UFSM), Mestrado em Engenharia Agrícola - Área das Ciências Rurais pela UFSM e Doutorado em Agronomia pela UFSM. Professora Adjunta III - Mestrado em Ensino de Humanidades e Linguagens- Universidade Franciscana (UFN). E-mail: elsbeth.geo@gmail.com. 


\title{
MULTIMODAL DIDACTIC RESOURCES AND TECHNOLOGIES IN GEOGRAPHY AND HISTORY TEACHING IN THE POST-MODERNITY
}

\begin{abstract}
In this article, we present the postmodern condition of the contemporary student, influenced by technologies and with access to the plurality of text and image resources, and the school, still formatted in a traditional teaching models. The research clipping in this article is anchored in the curricular components of Geography and History in Elementary School. Faced with the mismatch between school and student, we have bring indications of possibilities for using multimodal didactic resources as a more attractive and significant teaching-learning option in the postmodern scenario. With regard to methodological procedures, a bibliographical research was carried out on postmodernity and postmodern subjects, the teaching practices of Geography and History, and the multimodalities and didactic resources. The analyzes of the references point to the importance of the use of multimodal teaching technologies and resources in the teaching of these disciplines as fundamental in the formative itinerary of students in the present time.
\end{abstract}

Keywords: students; teaching-learning; text; image.

\section{INTRODUÇÃO}

A sociedade contemporânea é caracterizada por intensas e constantes transformações que se desencadearam, em ritmo cada vez mais acelerado, a partir da década de 1970, no período técnico-científico-informacional.

No livro "A condição Pós-moderna", David Harvey (1992) defende a tese de que, a partir de 1972, mudanças abissais ocorreram, transformando as maneiras de experimentar o tempo e o espaço. Assim, ocorre a ascensão de formas culturais pós-modernas, a emergência de modos mais flexíveis de acumulação do capital e início de um novo ciclo de compressão do espaço e do tempo. Disso decorreu um processo que produziu profundas mudanças estruturais e funcionais e introduziu significativa transformação na sociedade, que afetaram também a escola e a forma de entendimento/leitura do mundo empreendida pelos alunos do século XXI.

O atual contexto é caracterizado pela complexidade onde os sujeitos se apresentam de maneira plural. O "novo homem", o homem pós-moderno, assume algumas características, assinaladas por Bauman (2000), como conviver facilmente com as diferenças, ter o imediatismo como regra, entender que a novidade deve ser vivenciada e experimentada sem compromissos, mudar de ideias e posicionamentos com frequência, e não aceitar valores culturais e sociais impostos.

Esse processo produz o sujeito pós-moderno, conceitualizado como não tendo uma identidade fixa, essencial ou permanente. Hall (2006, p. 13), afirma que "a identidade torna-se uma 'celebração móvel': formada e transformada continuamente em relação às formas pelas quais somos representados ou interpelados nos sistemas culturais que nos rodeiam".

O homem da pós-modernidade se caracteriza na evidência do "líquido" e do "fluído", ou seja, na definição de Bauman (2000), a "sociedade líquida" que 
se efetua na aceitação do efêmero, do caótico, do pluralismo, da fragmentação e do temporário. Uma sociedade esquizofrênica e impactada na perda (planejada) da profundidade. Harvey (1992, p. 12), aponta a modernidade como implicando não apenas "um rompimento impiedoso com toda e qualquer condição precedente", mas como "caracterizada por um processo sem-fim de rupturas e fragmentações internas em seu próprio interior".

A sociedade caracterizada pelos avanços das tecnologias, das mídias (TV e cinema) e do capital, na percepção e na intervenção no espaço e no tempo (HARVEY, 1992), não consegue lidar com "seu novo jeito de ser" caracterizada pela efemeridade. "As práticas sociais são constantemente examinadas e reformadas à luz das transformações recebidas sobre aquelas próprias práticas, alterando, assim, constitutivamente, seu caráter" (GIDDENS, 1990, p. 37-38).

Giddens (1990, p. 6), reforça a ideia de uma dinâmica planetária, incessante e rápida, ao afirmar que "à medida em que áreas diferentes do globo são postas em interconexão umas com as outras, ondas de transformação social atingem virtualmente toda a superfície da terra". Esse cenário mutante em todo o globo terrestre reflete diretamente nas produções dos estudantes e na prática docente. Nessa perspectiva, a temática deste estudo é o ensino de Geografia e de História, na pós-modernidade considerando as possibilidades das multimodalidades e das tecnologias.

A intencionalidade do ensino na pós-modernidade, segundo Morin (2003, p. 11), "é transmitir não o mero saber, mas uma cultura que permita compreender nossa condição e nos ajude a viver, e que favoreça, ao mesmo tempo, um modo de pensar aberto e livre". Nesse sentido, a escola é um local privilegiado para desenvolver o conhecimento pertinente, que é para Morin (2003, p. 15)

[...] capaz de situar qualquer informação em seu contexto e, se possível, no conjunto em que está inscrita. Podemos dizer até que o conhecimento progride não tanto por sofisticação, formalização e abstração, mas, principalmente, pela capacidade de contextualizar e englobar.

O conhecimento pertinente busca superar a hiperespecialização ${ }^{4}$ da ciência moderna que fragmentou o conhecimento escolar em disciplinas estanques com conceitos distantes do espaço e do tempo dos estudantes, voltado para atender as necessidades da sociedade capitalista. As humanidades, com destaque para a Geografia e a História, frente ao ensino tecnocrático perderam espaço silenciando o pensamento crítico, colocando em risco os sistemas democráticos que podem se transformar em autoritarismos (ROUANET, 1987).

Somado a isso, as tecnologias "roubaram" o espaço do ensino tradicional e despertaram o interesse do jovem pós-moderno para a instantaneidade e às imagens.

4 Hiperespecialização, segundo Morin (2003, p. 13), é “a especialização que se fecha em si mesma sem permitir sua integração em uma problemática global ou em uma concepção de conjunto do objeto do qual ela considera apenas um aspecto ou uma parte". 
Segundo Carlson (2007), os nascidos entre 1982 e 2002, os Millennials ou Geração $\mathrm{Y}^{5}$ são mais familiarizados com a diversidade do que com o tradicional e isso influencia a maneira como veem os estudos e o trabalho, buscando frequentemente formas de misturá-los com o lazer e rejeitando modelos e rotinas engessadas.

Em um mundo em que a tecnologia evolui em uma enorme velocidade e proporciona revoluções em diferentes campos e espaços, as escolas ficaram atreladas aos seus métodos de ensino do início do século XX, apesar de seus alunos estarem mais expostos do que nunca às novidades tecnológicas e submersos na cultura da pós-modernidade.

Tem-se, portanto, uma dicotomia entre escola/professores e a geração de alunos submersa na cultura pós-moderna e no pragmatismo das tecnologias. Desse modo, o presente estudo se justifica, pois coloca em evidência o descompasso existente entre escola/professor e aluno (da geração Y) no ensino de Geografia e de História e, a partir disso, reflete e traz abordagens híbridas que privilegiam a multimodalidade e o uso das tecnologias.

"Em um mundo cada vez mais interconectado, passamos a interagir em uma gama mais ampla de práticas textuais (por exemplo, vídeos podem ser editados e postados na Internet, documentos podem ser enviados em intervalos de segundos ou compartilhados simultaneamente)" (NASCIMENTO, BEZERRA, HERBELE, 2011, p. 530) que produzem novas formas de ver a realidade e de compreensão do espaço geográfico.

Esse processo transformador refletiu diretamente no ambiente escolar, fazendo com que as interfaces digitais passem a conviver mutuamente e possibilitem interpretar e compreender a realidade de forma mais abrangente e complexa. Neste sentido, é relevante compreender o ensino de Geografia e História no contexto da multimodalidade ou, como coloca Rojo (2013), das linguagens líquidas e das criações conjugadas.

Isso posto, o ensino adquire uma linguagem hidrida exigindo novos (multi) letramentos e entendimentos dos recursos aos quais se associa como a imagem, $\mathrm{O}$ hipermídia, o multimídia, o mapa mental e, diante disso, o ambiente educacional torna-se multimodal viabilizando o desenvolvimento de metodologias, capacitações e pesquisas que integrem as mais diversas áreas e, entre elas, as tecnologias e as humanidades.

5 Geração que em pouco tempo de vida presenciou os maiores avanços na tecnologia e na comunicação eletrônica, cresceu em meio a um clima político global inconstante e com grande exposição à cultura popular e à diversidade. Não respeita modelos tradicionais e tem dificuldade de concentração em uma tarefa só (CARLSON, 2007).

6 Linguagem híbrida, segundo Rojo (2013), é aquela que mescla múltiplas linguagens, isto é, o mapa, o texto, a imagem, o som. Essa forma de linguagem é marcado por um processo de desterritorização e de descoleção, onde cada pessoa pode fazer sua própria coleção e manifestar-se por meio de múltiplas linguagens, em especial, pelas novas tecnologias. 
O artigo baseia-se numa pesquisa bibliográfica sobre a relevância da utilização das tecnologias e das multimodalidades no ensino de Geografia e História. Assim, o estudo encontra-se dividido em três subtítulos, a saber: $A$ pós-modernidade e os sujeitos pós-modernos; As práticas docentes de Geografia e História; As multimodalidades e os recursos didáticos.

\section{A PÓS-MODERNIDADE E OS SUJEITOS PÓS -MODERNOS}

A pós-modernidade está relacionada com a concepção de tempos e espaços múltiplos, que permitem ao ser humano uma infinidade de possibilidades interferindo no seu modo de vida e proporcionando constantes transformações em qualquer esfera da vida social. Interliga o local e o global de maneira desconexa, ou seja, preservam os costumes, a cultura local e incorporam novas tendências geradas na globalização. Essas características da contemporaneidade estão presentes na escola e nas práticas de ensino.

Para compreender a emergência do cenário pós-moderno e seus desdobramentos busca-se em Harvey (1992, p. 8):

Vem ocorrendo uma mudança abissal nas práticas culturais, bem como político-econômicas, desde mais ou menos 1972. Essa mudança abissal está vinculada à emergência de novas maneiras dominantes pelas quais experimentamos o tempo e o espaço. [...] Mas essas mudanças, quando confrontadas com as regras básicas de acumulação capitalista, mostram-se mais como transformações da aparência superficial do que como sinais do surgimento de alguma sociedade pós-capitalista ou pós-industrial inteiramente nova.

Assim, ocorre uma reorganização do sistema capitalista que gera o consumismo, ampliação de mercados globais e avanços tecnológicos que paulatinamente alteram as relações humanas (HARVEY, 1992). Nessa linha de pensamento entende-se que a dualidade entre ética e estética decorre das novas interconexões entre tempo e espaço que desencadeiam no individualismo, no descarte e nas incertezas, ou seja, a valoração da estética sobre a ética. Harvey (1992, p. 293), destaca:

A experiência do tempo e do espaço se transformou, a confiança na associação entre juízos científicos e morais ruiu, a estética triunfou sobre a ética como foco primário de preocupação intelectual e social, as imagens dominaram as narrativas, a efemeridade e a fragmentação assumiram precedência sobre verdades eternas e sobre a política unificada e as explicações deixaram o âmbito dos fundamentos materiais e político-econômicos e passaram para a consideração de práticas políticas e culturais autônomas.

Giddens (1991, p. 8), analisa o cenário pós-moderno a partir da modernidade e suas descontinuidades que ultrapassou os limites geográficos da Europa e atingiu influência em nível mundial e nos dias atuais

[...] estamos no limiar de uma nova era, a qual as ciências sociais devem responder e que está nos levando para além da própria modernidade. Uma estonteante variedade de termos tem sido sugerida para esta transição, alguns dos quais se referem positivamente à emergência de um novo tipo de sistema 
social (tal como a "sociedade da informação" ou a "sociedade de consumo") [...] Alguns dos debates sobre estas questões se concentram principalmente sobre transformações institucionais, particularmente as que sugerem que estamos nos deslocando de um sistema baseado na manufatura de bens materiais para outro relacionado mais centralmente com informação.

Os efeitos das descontinuidades geradas pelos avanços da informação são a globalização e o caráter reflexivo que pode ser entendido como a busca confusa pelo novo conhecimento, ou informação, que ressignifica constantemente a vida social (GIDDENS, 1991).

As modificações sociais da contemporaneidade, outrora simbolizadas na globalização, se reestruturaram e os valores modernos, pautados na rigidez, são substituídos pela necessidade de mudança e adaptação ao novo. A concepção que o mundo poderia ser gerenciado graças às teorias de longa duração não encontra local para prosperar, visto que com os avanços nas comunicações foram estabelecidas novas formatações entre o local e global.

Bauman (2001, p. 8), utiliza a expressão sociedade líquida como metáfora para explicar a dinamicidade da vida social na pós-modernidade, pois os líquidos "diferente dos sólidos, não mantêm sua forma com facilidade". Dessa maneira, liquidez e fluidez permitem compreender a essência do tempo presente caracterizado pela mobilidade, instantaneidade e novos padrões culturais e sociais. Bauman (2001, p. 13-14), acrescenta:

O que está acontecendo hoje é, por assim dizer, uma redistribuição e realocação dos "poderes do derretimento" da modernidade. Primeiro eles afetaram as instituições existentes, as molduras que circunscreviam o domínio das ações-escolhas possíveis, como estamentos hereditários com sua alocação por atribuição, sem chance de apelação. Configurações, constelações, padrões de dependência e interação, tudo isso foi posto a derreter no cadinho, para ser depois novamente moldado e refeito; essa foi a fase do "quebrar a forma" na história da modernidade inerentemente transgressiva, rompedora de fronteiras e capaz de desmoronar.

Essa conjuntura possibilita a formação de novas identidades e um novo modelo de sujeito, descrito por Hall (2006, p.10), como "sujeito pós-moderno". O sujeito pós-moderno distancia-se da identidade consolidada numa lógica estável e adquire um formato fragmentado, que para Hall (2006, p. 12), é "composto não de uma única, mas de várias identidades, algumas vezes contraditórias ou não resolvidas".

O sujeito pós-moderno é assim descrito por Hall (2006, p. 12-13), como "não tendo uma identidade fixa, essencial e permanente. A identidade torna-se uma celebração móvel". Isso decorre da expansão dos sistemas de significação e representação cultural que possibilita aos sujeitos uma diversidade de identidades, que se identificam com o espaço e o tempo em que vivemos.

A imprescindibilidade de rever as práticas de ensino para atender os sujeitos pós-modernos evidencia-se em Morin (2003, p. 9), fundamentos para uma 
ressignificação do ensino e do conhecimento abordado nas escolas, pois defende "a necessidade de uma reforma do pensamento, portanto uma reforma do ensino".

A missão do ensino é fornecer subsídios para compreendermos a heterogeneidade das relações sociais e desenvolvermos uma forma de pensar aberta e livre permeada de possibilidades (MORIN, 2013). Nessa lógica, o ensino e a escola são lugares de construção do conhecimento, superando a fragmentação deste em disciplinas estanques em prol de um conhecimento inter-relacionado e contextualizado.

Para Morin (2003, p. 15), a escola atual perpetua em sua prática o trabalho com os saberes fragmentados, ao invés de contextualizá-los, pois:

$\mathrm{Na}$ escola primária nos ensinam a isolar os objetos (de seu meio ambiente), a separar as disciplinas (em vez de conhecer suas correlações), a dissociar os problemas, em vez de reunir e integrar. Obrigam-nos a reduzir o complexo ao simples, isto é, a separar o que está ligado; a decompor, e não a recompor; e a eliminar tudo que causa desordens ou contradições em nosso entendimento.

A partir do exposto, o conhecimento pertinente torna-se a busca primordial do ensino, sendo a contextualização a premissa para atender os sujeitos pósmodernos. Visto que, diariamente estes sujeitos são bombardeados com conhecimentos compartimentados e muitas vezes sem a capacidade de articulação, pois esta capacidade está distante dos sistemas de ensino.

Frente aos aspectos constituintes da sociedade pós-moderna e seus desdobramentos no ensino, evidencia-se a necessidade de ressignificar as práticas docentes de Geografia e História, associando-as ao uso das tecnologias e dos recursos multimodais visando aproximar os estudantes do ambiente escolar e tornar a aprendizagem significativa7.

\section{PRÁTICAS DOCENTES: GEOGRAFIA E HISTÓRIA}

Nas circunstâncias atuais, caracterizada pelas incessantes e constantes transformações em todas as esferas da vida social, o professor é desafiado a todo o momento a rever a sua prática pedagógica. Contudo, frente ao desmantelamento das certezas construídas ao longo da modernidade, sobretudo no que relaciona a escola como detentora e centro único da difusão do conhecimento, as incertezas povoam a prática docente.

Alonso (2003, p. 10), descreve os dilemas enfrentados pelo professor nos dias atuais como sendo

7 Aprendizagem significativa de acordo com os Parâmetros Nacionais Curriculares (Brasil, 1997, p. 38) "implica necessariamente, o trabalho simbólico de "significar" a parcela de realidade que se conhece. As aprendizagens que os alunos realizam na escola serão significativas à medida que conseguirem estabelecer relações substantivas e não arbitrárias entre os conteúdos escolares e os conhecimentos previamente construídos por eles, num passo de articulação de novos significados". 
[...] muito difícil imaginar quais os melhores caminhos a seguir quando se pretende formar os jovens e as crianças, ou mesmo decidir sobre a conveniência de se ensinar esse ou aquele conteúdo disciplinar, tendo em vista as necessidades que eles terão, ou os problemas que deverão enfrentar. Mais grave ainda, não estamos seguros quanto aos valores, atitudes e comportamentos que deveriam ser estimulados para permitir que esses jovens convivam harmoniosamente com pessoas muito diferentes, provindas das mais variadas raças e culturas, expressando-as em línguas diferentes da sua, com ideias, crenças e religiões as mais variadas.

A educação tradicional fundamentada na transmissão de informações e na simples memorização de conteúdos por parte dos estudantes não mais encontra espaço no cotidiano escolar. As orientações curriculares para o Ensino Fundamental do município de Santa Maria, RS (2014, p. 86), sinalizam a postura que o professor deve assumir para aproximar-se da escola nos dias atuais, fundamentada "no estabelecimento de uma relação dialógica aluno/aluno; aluno/professores; aluno/ escola a partir de princípios éticos, políticos e estéticos". Evidencia-se que a postura dialógica torna o ambiente educacional propício para a construção do conhecimento, tanto dos estudantes, quanto dos professores, e valoriza as diferentes visões de mundo.

Neste viés, Freire (2014, p. 107), salienta que o diálogo assegura uma "ação e reflexão" e, por conseguinte, ocorre entrelaçamento de saberes diversos que se distanciam da imposição de saberes acabados. Ao considerar os conhecimentos dos estudantes, o professor está promovendo uma significativa transformação no ambiente educacional, atribuindo um novo significado ao processo de ensinoaprendizagem com vistas ao desenvolvimento do aluno.

A prática pedagógica que considera o diálogo na sala de aula associa-se aos desafios dos dias atuais sendo capaz de envolver os estudantes e docentes no processo de ensino-aprendizagem, e segundo Beahrens (2005, p. 54), oportuniza um ensino que supere "a reprodução para a construção do conhecimento". Assim, afloram discussões que valorizam a reflexão, o estabelecimento de relações entre conteúdos curriculares e os novos valores e saberes que se constituem e se reorganizam num fluxo contínuo.

Beahrens (2005, p. 55), sinaliza que a ação pedagógica que viabiliza a construção do conhecimento e o desenvolvimento da capacidade crítica deve

[...] enfocar o conhecimento como provisório e relativo, preocupando-se com a localização histórica de sua produção. Precisa estimular a análise, a capacidade de compor e recompor dados, informações e argumentos. Acrescida da valorização da ação reflexiva e a disciplina tomada como capacidade de estudar, refletir e sistematizar o conhecimento instiga o aluno a reconhecer a realidade e refletir sobre ela.

Nessa perspectiva, o professor assume uma postura de mediador. Quanto ao estudante, por meio de pesquisas e conexões entre os saberes, torna-se um sujeito ativo capaz de produzir conhecimento e partilhar suas construções na sala de aula. O entrelaçamento destas posturas forma uma "teia" que articula a compreensão do 
ser humano e suas relações na totalidade (visão sistêmica), busca a transformação social com o diálogo e trabalhos coletivos (abordagem progressista), e supera a memorização do conhecimento fomentando a investigação e a criticidade (ensino com pesquisa) (BEAHRENS, 2005).

Com as transformações decorrentes do avanço técnico-científicoinformacional, a busca por ações que enriqueçam a prática docente, o uso das tecnologias revelam-se como possibilidades. Beahrens (2005, p. 56), acrescenta que a tecnologia, sobretudo com a utilização da internet "aparecem como suportes relevantes na proposição de uma ação docente inovadora". Rojo (2012, p. 7), também enfatiza sobre a presença das tecnologias na escola "é preciso que a instituição escolar prepare a população para o funcionamento da sociedade cada vez mais digital e também para buscar no ciberespaço um lugar para se encontrar, de maneira crítica, com diferenças e identidades múltiplas".

Ao introduzir as tecnologias na prática docente são desenvolvidas habilidades imprescindíveis no estudante, como o fortalecimento da cultura colaborativa, a criticidade frente à pluralidade de informações e o respeito às diferentes culturas. O uso das tecnologias devem convergir para a construção do conhecimento, como um suporte para o professor desencadear o processo de ensino-aprendizagem e de ressignificação dos saberes. Ao valorizar o diálogo, o uso das tecnologias e desafiar os estudantes a construção do conhecimento, o professor apresenta uma nova postura, que de acordo com Anastasiou (2004, p. 14)

[...] assistir ou dar aulas precisa ser substituído pela ação conjunta do fazer aulas. Nesse fazer aulas é que surgem as necessárias formas de atuação do professor com o aluno sobre o objeto de estudo e a definição, escolha e efetivação de estratégias diferenciadas que lhe facilitem esse novo saber.

Desta forma, o fazer docente converte-se em um ofício desafiador que exige do professor a capacidade de mobilizar os estudantes e tornar a construção do conhecimento um processo encantador e, para tanto, a reflexão da prática ${ }^{8}$ é substancial.

A prática docente de Geografia e História voltada à construção do conhecimento desencadeia processos de compreensão do mundo, considerando o espaço produzido pelos homens ao longo de suas vidas e oportuniza aos alunos a capacidade de se entenderem como sujeitos históricos. Esse encadeamento ocorre devido aos componentes curriculares de Geografia e História combinarem conhecimentos temáticos de suas áreas de conhecimento com a prática docente (CASTROGIOVANNI et al., 2011).

A construção do conhecimento geográfico e histórico ocorre por meio das inter-relações do sujeito com a realidade social na qual está inserido, portanto a

8 Reflexão da prática - o conceito de profissional reflexivo surgiu nos trabalhos de Donald Schön (1992, p. 7) sobre a epistemologia da prática profissional, para quem "o conhecimento prático consiste na reflexão na ação e na reflexão sobre a reflexão na ação". 
prática docente de Geografia e História, segundo Castrogiovanni et al. (2011, p 20), é pautada em

[...] analisar historicamente o Espaço Geográfico, esse que é o espaço de existência das mulheres e dos homens, e isto, em última instância, é compreender pela sua gênese e conteúdo, não apenas pela aparência ou forma. Quer dizer, é compreendermos o passado à luz do presente em função da transformação social, de um novo futuro. É um movimento, amplo, dinâmico e sem limites. E, nesse processo, o aluno deve ser visto como sujeito, mas também como um objeto histórico. Objeto, pois é condicionado, mas sujeito, pois é um ser inacabado e, consciente disso, pode transcender os próprios condicionantes históricos.

Ao entrelaçar o espaço geográfico e os processos históricos, contextualizandoos regional e globalmente, os docentes de Geografia e História estão preparando os estudantes para o enfrentamento das situações problemas que surgem cotidianamente tornando-os sujeitos ativos e com potencial transformador da realidade. Nesta lógica, a sala de aula torna-se um espaço de relações onde docentes e discentes ressignificam os saberes e edificam novos conhecimentos (SCHMIDT; CAINELLI, 2004).

Após as averiguações sobre as práticas docentes de Geografia e História, passamos a abordar as possibilidades das multimodalidades e dos recursos didáticos na aulas destes componentes curriculares.

\section{AS MULTIMODALIDADES E OS RECURSOS DIDÁTICOS}

Aproximar a escola do estudante requer, nos dias atuais, novos olhares e novas práticas pedagógicas. Nesta esteira, os recursos didáticos multimodais apresentam-se como possibilidades de respostas aos anseios da geração $Y$, e também para que os professores construam o conhecimento juntamente com os estudantes, estabelecendo uma sinergia entre os sujeitos da educação.

A utilização de recursos didáticos multimodais está presente na escola de diversas maneiras: por meio da utilização de livros didáticos que valorizam a interrelação entre o texto escrito e as imagens, pelo uso de filmes, músicas, hipertextos, histórias em quadrinhos, entre outros recursos. No entanto, devido a escola ainda manter-se dentro de uma formatação moderna que valoriza a fragmentação dos conteúdos e a hiperespecialização, resta conforme Silva (2008, p. 1), refletir "como esses recursos são explorados de fato pelo seu caráter multimodal".

Nessa perspectiva, Rojo (2012, p. 11), sinaliza para a "necessidade de uma pedagogia dos multiletramentos". A temática dos multiletramentos no ensino remonta a um colóquio realizado em 1996, em Nova Londres (EUA), pelo Grupo 
de Nova Londres9 (GNL) que resultou num manifesto intitulado Pedagogy of Multiliteracies - Designing Social Futures. Nesse manifesto, o GNL sinalizava para a escola considerar, em sua prática, a multiplicidade de letramentos e culturas disponíveis, lembrando que nesse momento histórico houve uma grande disseminação das tecnologias da informação e comunicação, conhecidas como TICS (ROJO, 2012).

Para Rojo (2012, p. 13), na atualidade, faz-se necessário distinguir "letramentos múltiplos" de "multiletramentos". Os letramentos múltiplos nada mais são que a quantidade de recursos, ou práticas letradas disponíveis na sociedade. Os multiletramentos, de acordo com Rojo (2012, p. 13)

[...] aponta para dois tipos específicos e importantes de multiplicidade presentes em nossas sociedades, principalmente urbanas, na contemporaneidade: a multiplicidade cultural das populações e a multiplicidade semiótica de constituição dos textos por meio dos quais ela se informa e se comunica.

Os multiletramentos, portanto, contemplam a multiculturalidade associada à pluralidade de textos. Tem-se, dessa forma, o hibridismo, pois os textos contemplam uma diversidade de letramentos e de conhecimentos, sejam de cunho popular ou erudito. Nessas circunstâncias, proliferam os mais variados tipos de textos, os quais, por sua vez, passam a constituir o universo social e escolar.

Rojo (2012, p. 16), sinaliza que, no momento presente, os educadores assumam uma "nova ética" fundamentada no diálogo e menos em certezas construídas ao longo da modernidade e uma "nova estética" em que o educador passe a respeitar os padrões estéticos do outro. Nesse ínterim, os textos contemporâneos para Rojo (2012, p. 19), são "compostos de muitas linguagens (ou modos, ou semioses) e exigem capacidades e práticas de compreensão e produção de cada uma delas (multiletramentos) para fazer significar”. Por conseguinte, multimodalidades são textos que constituem ou exigem multiletramentos para sua compreensão e, assim, compor o ensino híbrido.

Os textos compostos por multiletramentos apresentam alguns traços em comum, pois, em sua maioria, são interativos e colaborativos, não estão presos em relações de poder e são híbridos (ROJO, 2012). São estes os textos disponíveis aos estudantes na sociedade e saber escrever, ler e compreender os multiletramentos torna-se imprescindível no fazer pedagógico, não por meio da regulamentação, impondo regras ao uso, mas sim pela valorização de suas potencialidades de pesquisa, de conexão com a complexidade configurando um cenário propício à construção do conhecimento.

Em relação à prática da pedagogia dos multiletramentos, Rojo (2012, p. 29), apresenta o "mapa dos multiletramentos" (Figura 1) desenvolvido pelo GNL. Em

9 Grupo de Nova Londres (GNL): trata-se de um grupo de pesquisadores de letramentos reunidos na cidade de Nova Londres, Connecticut nos Estados Unidos, composto por Courtney Cazden, Bill Cope, Mary Kalantzis, Norman Fairclough, Jim Gee, Gunter Kress, Alan e Carmen Luke, Sara Michaels e Martin Nakata (ROJO, 2012). 
linhas gerais, trata-se de um diagrama que visa a formar um estudante funcional frente aos textos contemporâneos, contemplando em suas fases, ou quadrantes, a análise crítica (seleção prévia do texto), a criação de sentido (entender o texto e a tecnologia utilizados em sua elaboração), a transformação (utilização do texto na vida social) e, finalmente a funcionalidade do estudante, que pode ser entendida como a competência para a utilização prática do texto (ROJO, 2012).

Figura 1 - Mapa dos multiletramentos

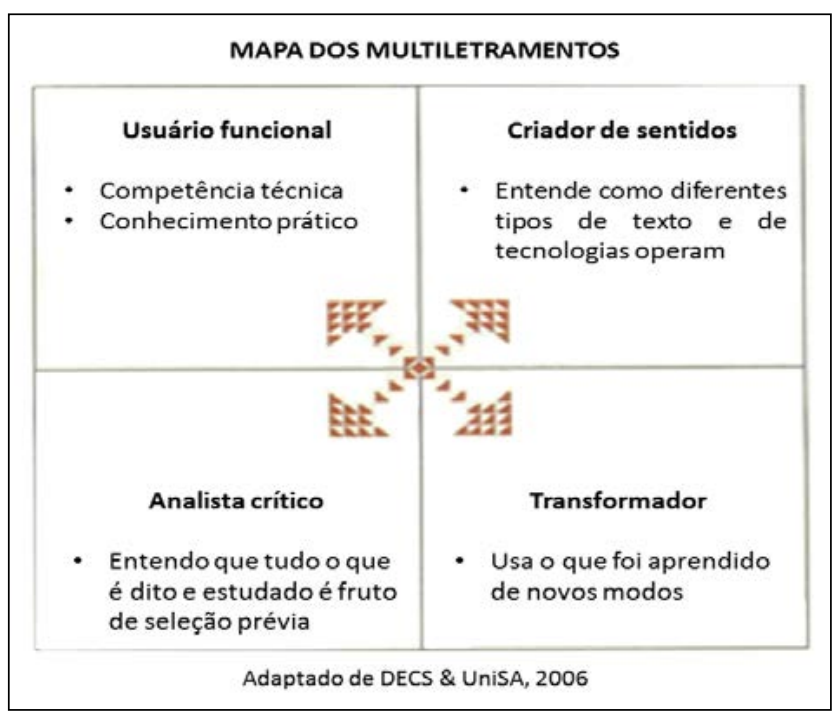

Fonte: Rojo (2012, p. 29).

A interdependência dessas fases/quadrantes (que compõem o mapa dos multiletramentos) desloca o estudante do papel de mero receptor de informações, apático e estático frente a um conhecimento já construído, para um estudante ativo, crítico e capaz de construir novos conhecimentos. Essa postura permite à escola aproximar-se da sociedade contemporânea, que se ressignifica a todo instante. E neste sentido, torna-se urgente compreender a História no espaço e a Geografia no tempo e no contexto das múltiplas linguagens ou, como sustenta Rojo (2013), das linguagens líquidas, das criações conjugadas e da aprendizagem colaborativa. Para isso, é indispensável ressaltar a abordagem dos multiletramentos e da multimodalidade nas disciplinas nos diferentes níveis e modalidades da Educação Básica como fonte de aprendizagem sobre o mundo contemporâneo.

A partir destes pressupostos, a prática docente de Geografia e História busca romper com a transmissão de conceitos de forma acabada e tornar o estudante um construtor de conhecimento. Além de sustentar sua ação no diálogo e no uso das tecnologias digitais, necessita observar criticamente a utilização dos livros didáticos. Os livros didáticos nas aulas podem significar a manutenção de um status quo ou a abertura a um processo de ensino híbrido e a interação do estudante com o 
conhecimento, pois muitos valorizam o uso de textos visuais ${ }^{10}$ concomitante com textos verbais permitindo contextualizar os saberes.

Cabe ressaltar que quando se fala/escreve sobre linguagem híbrida, segundo Rojo (2012), refere-se àquela que é multimodal, ou seja, mescla múltiplas linguagens: o mapa, o texto, a imagem e o som. Essa "nova" forma de linguagem é marcada por um processo de desterritorização e de descoleção, onde cada pessoa pode fazer sua própria coleção e se manifestar, opinar e/ou influenciar pessoal e digitalmente, por meio de múltiplas linguagens, em especial, pelas novas tecnologias, independente do lugar do mundo em que se encontre e da cultura que a envolve (ROJO, 2012).

Portanto, essa perspectiva híbrida do ensino de Geografia e de História emerge como uma nova fonte de debate que merece atenção e envolvimento dos pesquisadores voltados às metodologias de ensino da área, especialmente no que tange ao ensino híbrido. Ensino híbrido, ainda, significa:

[...] misturado, mesclado, blended. A educação sempre foi misturada, híbrida, sempre combinou vários espaços, tempos, atividades, metodologias, públicos. Esse processo, agora, com as mobilidades e a conectividade, é muito mais perceptível, amplo e profundo: é um ecossistema mais aberto e criativo. Podemos ensinar e aprender de inúmeras formas, em todos os momentos, em múltiplos espaços. Híbrido é um conceito rico, apropriado e complicado. Tudo pode ser misturado, combinado, e podemos, com os mesmos ingredientes, preparar diversos "pratos", com sabores muito diferentes (MORAN, 2015, p. 27).

Os recursos didáticos multimodais nos livros didáticos de Geografia e História, associadas ou não a outros recursos e infraestruturas escolares, como softwares, permitem ensinar e aprender sobre a realidade de formas diversas, criativas e com inovação pedagógica. Por outro lado, a linguagem líquida e híbrida dos livros, dos mapas, dos vídeos e dos aplicativos na contemporaneidade, possibilitam ao indivíduo (e ao aluno) tornar-se leitor-autor desses produtos independente do espaço geográfico ou do período histórico do fenômeno a ser estudado, na medida que interage com diversos recursos textuais produzindo novos significados e compreensões, convertendo-se em construtor de novos conhecimentos. A arte da leitura ocorre a partir da interação do leitor com seus conhecimentos prévios e os textos não são só aqueles formados por palavras e frases, que se encadeiam para ganhar sentido. Os grafites nas ruas, os comerciais de televisão (ou outras mídias), as gravuras em livros e as pinturas de obras de arte são formados por sinais que, muitas vezes, são decodificados pela vivência e sensibilidade para serem compreendidos. Somados aos textos verbais, essas linguagens ajudam os alunos a

10 Textos visuais comportam imagens com significações que são concebidas a partir da interação texto (imagem)/leitor/contexto. Nesse sentido, as imagens são constituídas pelo intuito do autor, pela estrutura e pelo seu conteúdo, logo, o procedimento de leitura ocorre através da interação do leitor com seus conhecimentos prévios; a imagem com os objetivos do autor; e o contexto no qual está inserida (PIETROFORTE, 2010). 
interagir com o mundo e a se expressar a partir do seu mundo vivido e dos saberes nos livros didáticos.

\section{CONSIDERAÇÓES FINAIS}

Esse artigo teve por finalidade investigar, por meio de pesquisas bibliográficas, as práticas pedagógicas dos docentes de Geografia e História no contexto atual, bem como compreender o descompasso entre a escola, professores e estudantes que gera a desmotivação no percurso formativo dos estudantes, ocasionando desistências, reprovações e distorções entre idade e ano nas escolas brasileiras.

Apresentamos como possibilidade de aproximação entre esses atores que constituem o cenário educacional a utilização das tecnologias e das multimodalidades nas aulas de Geografia e História. Entende-se que ao considerar estas possibilidades se estabelece uma sinergia entre os estudantes, sujeitos pós-modernos, e a escola tornado o ensino atrativo, desafiador. Essa compreensão viabiliza aos alunos estabelecerem relações entre os conteúdos e a realidade que os cerca, emitindo diferentes compreensões e significados, tornando a escola um espaço plural, construindo assim novos conhecimentos e contribuindo no itinerário formativo dos estudantes.

\section{REFERÊNCIAS}

ALONSO, M. Formar professores para uma nova escola. In: $\mathbf{O}$ trabalho docente: teoria e prática. São Paulo: Pioneira Thomson Learning, p. 9-18, 2003.

ANASTASIOU, L, G, C. Ensinar, aprender, apreender e processos de ensinagem.

Processos de ensinagem na universidade: pressupostos para as estratégias de trabalho. Joinville: UNIVILLE, p. 11-35, 2004.

BARTH, L. W. O homem pós-moderno, religião e ética. Teocomunicação. Porto Alegre, v. 37 , n. 155 , p. $89-108$, mar. 2007.

BAUMAN, Z. A modernidade líquida. São Paulo: Zahar. 2000.

BEHRENS, M. A. O paradigma emergente e a prática pedagógica. Petrópolis: Vozes, 2005.

BOFF. L. Tempo de transcendência: o ser humano como projeto infinito. Rio de Janeiro: Sextante, 2000.

BRASIL. Ministério da Educação. Secretaria de Educação Média e Tecnológica. Parâmetros Curriculares Nacionais: introdução aos Parâmetros Curriculares

Nacionais. Brasília: Ministério da Educação, 1997. Disponível em: <http://portal.mec. gov.br/seb/arquivos/pdf/livro01.pdf > . Acesso em: 15 de maio de 2017.

CASTROGIOVANNI, A. C. et. al. Ensino de Geografia: caminhos e encantos. Porto Alegre: PUCRS, 2011. 
CARLSON, S. The Net Generation in the Classroom. The Choronicle of Higher Education, ago. 2007. Disponível em: <http://chronicle.com/free/v52/i07/07ao3401. htm >.Acesso em: 13 set. 2016.

FREIRE, P. Pedagogia do oprimido. 57. ed. Rio de Janeiro: Paz e Terra. 2014.

GIDDENS, A. As consequências da modernidade. São Paulo: UNESP, 1991.

HALL, S. A identidade cultural na pós-modernidade. 11. ed. [Trad. Tomaz Tadeu da Silva; Guacira Lopes Louro] São Paulo: DP\&A, 2006.

HARVEY, D. A condição pós-moderna. 17. ed. [Trad. Adail Ubirajara Sobral; Maria Stela Gonçalves] São Paulo: Loyola, 1992.

MORAN, J. M. A educação que desejamos: novos desafios e como chegar lá. 5. ed. Campinas: Papirus, 2015.

MORIN, E. A cabeça bem feita. São Paulo: Cortez, 2003.

NASCIMENTO, R. G; BEZERRA, F. A. S; HERBELE, V. M. Multiletramentos: iniciação à análise de imagem. In: Linguagem \& Ensino. Pelotas, v.14, n.2, p. 529-552, jul./dez. 2011.

PIETROFORTE, A. V. Análise do texto visual. São Paulo: Contexto, 2010.

RUANET, S. P. As razões do iluminismo. São Paulo: Companhia das Letras, 1987.

ROJO, R. Pedagogia dos multiletramentos. In: Multiletramentos na escola. São Paulo: Parábola, 2012. p. 7-32.

ROJO, R. Apresentação. In: Escola conectada: os multiletramentos e as TICs. São Paulo: Parábola, 2013. P. 7 - 12.

SANTA MARIA. Orientações curriculares para o Ensino Fundamental. Rede Municipal de Ensino de Santa Maria, RS. 2014. Disponível em: <www.santamaria.rs.gov. br>. Acesso em: 25 out. 2016.

SILVA, G. G. Multimodalidade na sala de aula: um desafio. Pesquisas e discursos pedagógicos. Rio de Janeiro, v. 1, n. 2, p. 1-15, 2008. Disponível em: <https:/ /www. maxwell.vrac.puc-rio.br/12655/12655.PDFXXvmi>. Acesso em: 21 mar. 2017.

SHIMIDTH, M. A; CAINELLI, M. Ensinar história. São Paulo. Scipione, 2004. 